\title{
Towards decolonising a module in the pre-service science teacher education curriculum: The role of indigenous knowledge systems in creating spaces for transforming the curriculum
}

\section{Ronicka Mudaly}

Science Education, Science and Technology Cluster, University of KwaZulu-Natal, Durban, South Africa Mudalyr@ukzn.ac.za http://orcid.org/0000-0002-7347-2098

(Received: 5 May 2018; accepted: 6 November 2018)

\begin{abstract}
Post-apartheid South Africa has witnessed many changes in its quest for social justice. However, these changes have not affected South African higher education institutions (HEIs) that continue to privilege epistemic traditions that are embedded in Western frameworks. The science curriculum has been instrumental in promoting Western worldviews as being universal. This has resulted in normalising the subordination of nonWestern people and their knowledge systems. In seeking a change in the tenor of science education, I report on a qualitative study that explored the intersecting influence of the pre-service science teacher curriculum and indigenous knowledge systems (IKS). In my reconceptualising of a part of one science module, a departure from the revised curriculum and from the Western epistemic canon was effected by reframing who teaches, what is taught and how it is taught. A purposively selected sample of 224 pre-service teachers engaged in a field trip and a gardening project that was facilitated, in part, by an indigenous knowledge expert. Pre-service teachers planted a vegetable garden using indigenous methods and cultivated indigenous and non-indigenous plants. They captured the processes of planting and growing the plants in their portfolios and reflected on their learning by responding to questionnaires. I analysed the data drawn from the portfolios and replies to the questionnaires thematically. My findings revealed that consciousness-raising had occurred in these pre-service teachers about the value of indigenous knowledge (IK) and they endorsed the IK expert as a legitimate teacher in higher education. Insights into using IKS to transform and decolonise the curriculum by engaging an IK expert to teach brought previously marginalised IK to the centre. Teaching and learning in this context maximised interaction between the pre-service teachers and the materials being studied in their natural setting.
\end{abstract}

Keywords: decolonising, curriculum transformation, indigenous knowledge holder, pre-service science teachers, IKS

\section{Introduction and background}

The intellectual reliance of South African HEIs on knowledge systems of the US and Europe is undeniable. Western research methods and theories have become the gold standard in most 
countries (Connell, 2016). Curriculum ideologies, design, models, and textbooks from the Global North have dominated the intellectual culture and practices of most HEIs in the world and have reinscribed the valuing of "a single [Western] episteme" (Connell, 2016, p. 8). The epistemological traditions of South African HEIs whose curricula reflect the perpetuation of Western worldviews and privilege, reveals the complicity of these institutions in neglecting non-western knowledge systems (Heleta, 2016a; le Grange, 2016). Since 2015, the call to decolonise South African HEIs by incorporating other African and non-Western global epistemologies has become more insistent (Shay, 2016). The remaking of an intellectual culture and the greater democratisation of the university, in keeping with the society in which it finds itself, are required as precursors to major curriculum reform. I begin this article by discussing the national rationale for decolonising the university curriculum. Next, I discuss how IKS policy in South Africa applies to the school curriculum, and how some researchers have infused IKS into teacher education. A description of theoretical constructs drawn from African and other philosophers, and linked to curriculum theory, follows. I then provide a description of the qualitative case study methodology, explain the suitability of questionnaires and portfolios for the generation of data, and describe the sequence of activities in which these pre-service science teachers engaged to establish the gardens and grow the plants. My conclusion points to the need for pre-service teachers to rediscover and recover their cultural IK.

\section{Decolonising the curriculum}

At the macro-political level, debates about the curriculum are occurring nationally and HEIs are being strained in many ways. Amid physical and metaphorical fires, debates about who has access to education, educational justice, the whiteness of the university curriculum, universities as bastions of colonialism, and decolonising university curricula, among others, ensue.

Le Grange (2016), in exploring what decolonising the university curriculum might entail, drew on Chilisa's (2012) five phases of the process of decolonisation. These include "rediscovery and recovery; mourning; dreaming; commitment and action" (cited in le Grange, 2016, p. 3). Rediscovery and recovery involve colonised people exploring and reclaiming their culture and identity. Colonised people mourn their continued oppression, in this case through the university curriculum. Dreaming, in this instance, involves colonised people re-imagining an alternative university curriculum that is imbued with their IK. Commitment refers to the process of raising awareness of the muting of colonised people, here, in relation to the university curriculum, by politicians, academics, and students. Action refers to the implementation of strategies for change, which could, as far as this debate is concerned, take the form of university curricula that reflect a valuing of IK.

In an effort to conceptualise the notion of curriculum, le Grange (2014) referred to Pinar's (2011) and Wallin's (2010) understanding of curriculum as currere and encouraged us to "think of the curriculum as an active conceptual force" (p. 1287). In the dominant Western education system, the active force of the notion of currere has become restricted by 
ubiquitous Western ways of knowing and doing. This territorialisation of currere's active force (le Grange, 2014) has stifled its productive capacity and inhibited its potential for creativity. An "Ubuntu-currere", suggested by le Grange (2016, p. 9), can enable the transcendence of boundaries by our experimenting with creative pathways for living in the world where a unity of oneself with the human and non-human environment is promoted. Several possibilities have been presented to decolonise and Africanise the university curriculum (see le Grange, 2014, 2016). These include a rethinking of Western disciplines and examining their underlying philosophical and methodological paradigms. The possibility of incorporating IKS through the "deterritorialisation" of disciplines such as botany, for example, and its "reterritorialisation" (le Grange, 2014, p. 1288) into a sub-discipline such as ethnobotany, could be explored. This is linked to le Grange's vision for a decolonised curriculum based on an "emergent Indigenous paradigm" that includes, among other constructs, "relational accountability" (curriculum is accountable to other humans and the wider environment), and "respectful representation" (curriculum creates spaces for "voices and knowledges of indigenous peoples") (le Grange, 2016, p. 9). Decentring Western epistemology in university curricula and designing them to involve socially distributed knowledge systems which are relevant (but not limited) to local and regional contexts, is crucial (le Grange, 2014, 2016).

Other African intellectual analysts have added their insights on decolonising the curriculum. Letsekha (2013) proposed a "fundamental overhaul of the whole epistemological model underlying the current education system" (p. 9), and Molefe (2016) has argued for "ending the domination of Western traditions, histories and figures" (p. 32). Adopting a practical approach, Jansen (2017) contended that the presence of more black African curriculum theorists, who are research productive and intellectually imaginative, is crucial to the process of decolonising the curriculum. Alluding to decolonising teacher education curricula in particular, Sayed, Motala, and Hoffman (2017) have underscored the importance of an African-centered approach.

Connell (2016) argued that colonised people's knowledge formations have been devalued and disrupted, and it is this that helped create inequalities that are currently manifesting. Universities that seek to democratise themselves should address the challenge of the "reproduction of epistemological blindness that silences other knowledges and ways of creating knowledge" (Motta, 2013, p. 97), through curriculum. Ways of combating the continued erasure of the knowledge of the subaltern involve troubling the notion that "their only option is to blindly follow the 'enlightened' colonisers, learn from them, adopt their worldviews and fit into the periphery of their world as second-class citizens" (Spivak, 1994, cited in Heleta, 2016a, p. 4). Examining the interface between IKS and education has the potential to give visibility, voice, and agency to culturally marginalised people.

\section{IKS and Education}

Historically, the South African socio-political landscape has been characterised by a violation of human rights based on people's cultural affiliations and racial classification. While 
inequity was entrenched across social, economic, and cultural spheres, and impacted the geographical circumstances of non-white South Africans in general, indigenous communities, the holders of IK, and women were more severely affected. Practitioners and knowledge holders of IKS were oppressed, ridiculed, and devalued. A decade after the transition from a separatist to a democratic political order, the South African Government adopted the IKS Policy (Department of Science and Technology (DST), 2004) that sought to redress the inequity of marginalised people so as to "integrate and celebrate African perspectives in South Africa's knowledge systems" (DST, p. 10), and to affirm those cultural identities that had existed through observance of IK practices.

Education has been used as a vehicle to attain the goal of engaging in an "autonomous, selfreliant process of knowledge production [that] meets both the intellectual and material needs of African societies" (Hountonji, 2009, p. 9). One way of reclaiming cultural identity is to transform the curriculum into a culturally inclusive one. In South Africa, the post-apartheid school curriculum is developed within a social justice framework that underscores education for empowerment, self-sufficiency, and democratic participation. The attempts to recentre African knowledge are evidenced in colossal shifts in the school curriculum. In 1997, the call for teachers to include IKS in the school science curriculum was made, and this call has persisted in the relatively new Curriculum Assessment and Policy Statement (CAPS) (Department of Basic Education, 2011). The rationale for this, according to CAPS in the science subjects, is to enable learners to use IK in society and the environment. However, the successful enactment of this policy has been hindered by inadequate teacher education, among other things, and this has implications for teacher education programmes at universities (de Beer \& Petersen, 2016; Jautse, Thambe, \& de Beer, 2016).

Some studies of in-service teacher education that are linked to IKS are emerging. For example, Jautse et al. (2016) reported on how the North-West University leveraged human and material IK resources from the Mphebatho Museum located in Pilanesberg to address the need to enhance teacher knowledge about IKS. The museum offered a "conceptual and immersive space that stimulate[d] creative thinking and critical thinking" (p. 442) about the Bakgatla-ba-Kgafela culture. Findings revealed a heightened interest among teachers to learn about diverse cultures, and an increasing awareness among them about the need to infuse IKS into the science education curriculum.

The study by Jautse et al. (2016) referred to "epistemological border-crossing" (p. 442) and so did that by de Beer and Petersen (2016, p. 449) to link Western science to IKS. The latter advocated a socially distributed knowledge; teachers consider their own culture and IK and that of their learners to create a lived, relevant curriculum. They argued for a departure from "cookbook practicals" (de Beer and Petersen, 2016, p. 442) or, what Millar (2004) referred to as recipe type practicals that do not require the learner to think about what is being done. In their study, de Beer and Petersen (2016) described how teachers worked cooperatively to infuse IK into science curricula and concluded that this resulted in "demystifying IKS and decreas[ing] the marginalisation of IKS" (p. 458). 
Engagement with literature, which is becoming increasingly replete with diverse views of African philosophers about the ways in which the knowledges of Africans can bring African identity back to the centre of the curriculum, is crucial.

\section{Theoretical constructs}

A key focus of postcolonial African philosophy has been the "relationship between tradition and modernity" (Ciaffa, 2008, p. 121) and has triggered questions about the value of African Indigenous Knowledge (AIK) in addressing contemporary social challenges. Several African philosophers have aligned themselves to opposing perspectives in this regard. One perspective according to Gyekye (1997), as Ciaffa (2008) has reminded us, is cultural revivalism that aims to restore reverence for a traditional African heritage by revitalising African indigenous teachings. This perspective focuses on the disruptive and denigrating effects of colonialism on African cultural practices and colonised people. An opposing perspective criticises cultural revivalism as quixotic and contends that returning to traditional African teachings and practices does not meet the socio-political and economic challenges of contemporary Africa.

African philosophers, such as Kiti (2013), believe that African people have been enfeebled "socially, politically, religiously, technologically, economically and intellectually" (p. 1) because of their interaction with people of Euro-western descent, and this has driven African people to the margins of society. Kiti provides critical insight into the role of postcolonial Africa in global knowledge production. He concludes that Africa serves as the provider of "raw material" (p. 2) for intellectual production on a world-wide scale. For example, participants in clinical trials are often from Africa. What type of knowledge is produced, how it is produced, and who will benefit from this knowledge production are all controlled by nations in the Global North who are at the centre of knowledge production. Other African philosophers such as Hountonji $(1983,2009)$ call for Africans to reclaim their cultural identity by developing new modalities of producing knowledge, and for Africans to "re-learn how to think" (Hountonji, 1983, p. 53). In his later work, Hountonji (2009) advocates a reappropriation of African knowledge and calls for for a revival of "épistémologies du Sud" (p. 1).

A review of curriculum theories reveals how these liberatory philosophical insights influence the philosophy, direction, content, and pedagogy that underpin education systems. The insights of these African philosophers are linked to the tenets of the social reconstruction ideology informing curriculum studies that is based on social perspectives. This theory focuses on developing curricula by addressing problems of inequality that originate from oppressive policies and practices related to race, gender, and economic privilege or the lack thereof, among others. Social reconstructionists look to education in general, and the curriculum in particular, to facilitate consciousness-raising about social inequality, with a view to building a better society for all people. More specifically, social reconstructionists "consider human experience to be shaped most powerfully by cultural factors and assume that meaning in people's lives is determined by their social experiences" (Schiro, 2008, p. 6). 
Advocates of this ideology endeavor to stimulate re-thinking by curriculum practitioners and curriculum evaluators about the ways in which instruction is planned, the instructional methodologies employed, and the selection of textbooks and other curriculum resources linked to the content of the curriculum (see Schiro, 2008).

As a university curriculum practitioner, I decided to rethink the curriculum that informed a module that I had been teaching. I did this by focusing at a micro-level on critically redesigning a unit of work in a science education module. The structure of the module, and its location in my institutional culture, mirrored that of Connell's (2016) in ways that heightened my discomfort. Connell (2016) drew on Hountonji's views when she described her module in sociology as having

a global centre in the USA, secondarily in western Europe, almost all influential theory coming from the metropole; all prestigious journals published in the metropole; sociology in the periphery supplying data but intellectually dependent on the metropole; and careers in the periphery strongly affected by training and recognition in the metropole. (p. 9)

Before embarking on this study, I reflected on the curriculum related to the module I taught, and found that the content, pedagogy, and underlying philosophy was in keeping with a colonial education framework. In order to address the epistemic violence that the colonial education canon inflicts on students, I sought a new orientation to teaching and learning. This was achieved by re-appropriating IK and requesting support from an IK expert to teach part of the module. This university science education content module, which is studied by preservice science teachers, was changed to incorporate the teaching of IKS. In this paper, therefore, I provide insight into these pre-service teachers' perspectives about IKS education. I do so by focusing on the role of an IK holder as a teacher educator in higher education, and on the value the pre-service teachers attributed to her and to IK.

I focus on re-imagining this South African science curriculum in socially just ways that can contribute to Hountonji's "épistémologies du Sud." The new curriculum draws selectively on philosophical constructs of cultural revivalism and the intellectual independence espoused by African thinkers, as well as on the social reconstruction curriculum ideology of other theorists, in order to answer the question: "How can the incorporation of IKS into a unit of work transform and decolonise a science module in the higher education curriculum?" Teaching is not a neutral activity and the source of knowledge, as well as the people for whom it is intended, should be critically interrogated, as part of the process of decolonising the curriculum (Ruddock, 2018). I think that how one teaches, what one teaches, and why one teaches depends on the intended learner, among other things. In an autocratic political order, the learner is expected to passively accept received dogma. In a more liberal setting, it is expected that the learner will be sceptical and more critical.

What one teaches and how one teaches depends on one's view of reality and that of one's students. Bearing this in mind, I formulated two sub-questions. "What are pre-service teachers' views about being taught a unit of work in the science curriculum by an IK holder 
and how can this create spaces for transformation?" and "What indigenous knowledge can be learnt from an IK holder, and how can this be used to transform a unit of work in the curriculum?" I analysed these by examining ways in which the who, what, and how of incorporating IK into the curriculum created spaces for transformation and decolonisation.

\section{Methodology}

This was a phenomenological study that explored how some pre-service science teachers experienced a science education module that was infused with IK and taught by an IK expert. The IK expert was introduced to me by the principal of an Eco-school, which was the site of field trips that I had arranged for several cohorts of students over a period of time. Having been raised in a deeply rural setting, where knowledge of community elders was respected, the IK expert shared in the knowledge and practices of the community. She became an educator, continued to grow indigenous plants for food and medicine, and learned about the value of these plants from indigenous knowledge holders and from written texts.

A qualitative methodological approach underpinned this phenomenological study. Central to phenomenology are conscious human beings and their lived experiences (Groenewald, 2004). In this study the pre-service teachers' experience of being taught by an IK expert, and their experience of incorporating IK into science content knowledge, to understand how this way of doing things differently can work towards decolonising the curriculum, was explored. This involved designing activities to enable these pre-service teachers to rupture boundaries of familiar ways of knowing and doing — to take flight in different directions (see le Grange, 2014, 2016). Pre-service teachers were encouraged to enter a transdisciplinary space by including IK in their mainstream science content knowledge, and in this way, contribute to transforming and decolonising the science teacher education module, a part of the university curriculum.

The data generation instruments were questionnaires that were based on a field trip, and portfolios of evidence for vegetable and medicinal plant gardens. These instruments were designed to elicit how these pre-service teachers "[thought] and [felt] in most direct ways" (Bentz \& Shapiro, 1998, p. 96). They were encouraged to describe their lived experience, unconstrained by the conventional science content knowledge and by a conventional higher education teacher. In social science research, questionnaires are useful tools to generate information about people's perceptions, beliefs, attitudes, and behaviours (Bertram \& Christiansen, 2014; Strange, Forest, Oakley, \& The Ripple Team, 2003). Questionnaires were distributed to pre-service teachers who were asked to reflect on the field trip and provide their views about learning IKS, and about learning from an IK holder. The pre-service teachers were also required to cultivate gardens and document this process in a portfolio of evidence. According to Singh and Samad (2015) portfolios of evidence are suitable for capturing evidence of process-oriented tasks and are useful in assessing how students construct meaning through reflection. Therefore, these tools for generating data were well suited to this study. 
I invited the cohort of 224 pre-service teachers, who were registered to study the Biological Science for Educators 310 module, to participate in this study. This purposive sample was selected based on the following criteria: they were registered to study the Biological Science for Educators 310 module, attended the field trip, and cultivated gardens. However, only 50 pre-service teachers completed the questionnaires.

Normally, I taught this course along with a tutor but during the field trip an IK holder taught the pre-service teachers. She focused on ethnobotany to underscore the nutritional and medicinal value of African Indigenous plants. The participants were then requested to complete a questionnaire about their views and experiences related to the ethnobotany activities and the IK holder as a teacher educator. When they returned to the university campus, they cultivated vegetable and medicinal plant gardens for health, either on the campus or at schools in the communities where they resided. They worked in groups and engaged in the following activities.

- Made enquiries from health providers in community clinics about general health challenges that could be addressed through nutrition.

- Read about plants that they could cultivate in order to manage a community health condition. This knowledge was obtained from diverse sources, including notes from the ethnobotany activity, and published works (from Western and indigenous sources) on the value of indigenous plants.

- Selected a plot. Drew a plan of the garden. Indicated how the soil would be nourished and the pest control measures to be used (based on indigenous knowledge and permaculture education).

- Prepared the soil. Sowed the seeds and seedlings. Documented the growth using pictures.

- Reflected on the learning that occurred and the potential usefulness of this project to Life Sciences teachers.

\section{Data analysis and findings}

Following Gray (2013) I used thematic analysis for recognising and analysing patterns of meaning in the data. I coded data that had features related to decolonising the curriculum. The codes were then organised into themes (see Maree, 2016). I used symbols to indicate the data source. For example, QP1 contained data from the questionnaire completed by participant 1. Data from three portfolios was admitted, where GP1, for example, represents the garden portfolio from group 1. The first set of findings relates to the theme, the who and how of incorporating IKS into the curriculum, and how this enabled transformation. First, pre-service teachers' views on the pedagogy in general were elicited, and second, they compared my pedagogy as a higher education lecturer along with that of the tutor with how the IK holder taught. I analysed the next set of findings according to the what of incorporating IKS into the curriculum, and how this allowed for the possibility of transformation. In this section the pre-service teachers provided evidence of which plants they had cultivated, and the reasons for their choices. This infusion of IKS into the 
curriculum mirrored le Grange's (2016) vision of a decolonised curriculum based on an “emergent Indigenous paradigm" (p. 9).

\section{Theme 1: The who and how of incorporating IKS and creating spaces for} transforming the curriculum

Pre-service teachers were impressed by the pedagogy of the indigenous knowledge holder, and they enjoyed the learning experience, as is evident in the following excerpts.

QP1: She explained clearly ... had a loud voice. She was knowledgeable because she answered questions that were asked.

QP2: The traditional knowledge holder as a teacher in higher education is of paramount importance to the teaching and learning profession. She brings in new insights into the (previously) unknown traditional knowledge system. She has provided us with traditional knowledge that has benefited our health.

A reflection in GP3 resonated with these views in the replies to the questionnaires.

GP3: We absolutely enjoyed her because firstly woman power is amazing. It was also very fun and interesting learning from her because there was an open platform to ask anything. She was knowledgeable and loved what she was doing.

Pre-service teachers were asked whether learning from the IK holder was different when compared to learning from me and the tutor. The following responses were received, among others.

QP2: Learning from her was different from the lecturer because it was not educator centered and it promoted the spirit of communication and interaction.

QP5: Unlike here (at university) (the IK holder) did not passively teach ... [she] used plants themselves ... we were able to touch them when [she was] teaching.

QP7: [She] showed us everything... [we were] not just imagining things like in lectures [when] things are not shown to us.

QP38: We were allowed to feel texture, smell [plants] etcetera as compared to lectures where most of the work is theory based.

Similar views were expressed by the groups who reflected on the knowledge they had gained from the IK holder in their portfolios.

GP1: We enjoyed learning from her. She was very knowledgeable and the things she spoke about are not just things she has read or learned about but she literally has these trees and plants in her garden at home and she uses them on herself and her family as well. 
GP3: The IK holder was calmer in comparison to my lecturer. We felt we could ask her anything. We learnt that a lot of plants are easy for us to access and within our reach and have value that [we] did not know they had.

GP2: Learning from her was very interesting and exciting because she was talking from her experience. Everything she said were based on things she had tried, unlike from the lecturer where knowledge is [taken] from the textbook and then [given] to us.

Exploring the who and how of incorporating IKS into the curriculum raises a mirror to teachers in higher education. The pre-service teachers saw a marked difference in pedagogical approaches of the IK holder, as compared to the tutor and me as higher education teachers. They found the IK holder, as a pedagogue in higher education, to be superior to us because she adopted a practical, hands-on approach to knowledge construction. She provided them with specimens of plants and medicinal products derived from them. The IK holder encouraged pre-service science teachers to use their senses maximally in order to examine and interact with the plant materials. These creative ways of teaching that are underpinned by the oneness of self with the environment is an example of le Grange's "Ubuntu-currere" (2016, p. 9). The indigenous knowledge holder encouraged discussions among the pre-service teachers and facilitated peer learning. The pre-service teachers had greater confidence in her subject matter knowledge which they believed to have been constructed through lived experience and not simply acquired through transmission from a textbook. Her knowledge of instructional strategies, which involved an inquiry approach using concrete materials, was useful to these pre-service teachers. This created opportunities for thinking differently and transformatively about what constitutes useful pedagogical knowledge, and about some aspects of the identity of an authentic teacher in higher education.

Kincheloe (2011) described the Cartesian-Newtonian way of thinking, which shapes higher education science teacher curricula, as being characterised by a disconnect between that which is central to an inquiry and its context. In their lectures, pre-service teachers had to "imagine ... things that are not shown to us" when we privileged abstract content and "show[ed] [them] pictures." The methods employed by us as lecturer and tutor reminded me of le Grange's (2016) citation of Odora-Hopper and Richard's criticism of Western disciplinary knowledge as being "distant" (p. 9) and removed from lived experience. The IK holder's epistemology transcended simply knowing about medicinal plants. She adopted a pedagogical approach that privileged pre-service teachers' interaction with the physical environment and the plant specimens and encouraged their construction of knowledge in their being a part of the natural world, and not separate from it, and this represented a pathway toward curriculum transformation. The IK holder had deep synergy with what she taught, how she taught, and why she taught, and this probably stemmed from what Zinyeka (2013) refers to as a more comprehensive, holistic view of the world. Therefore, it was impossible to separate the who from the how of incorporating IKS into the curriculum, because the learning and teaching by the IK holder was embedded in her lived experience-in how she perceived her reality. This route towards the "becoming of a pedagogic life" where the IK holder immersed herself in the "more-than-human world" resonates with tenets of "Ubuntu-currere" 
as a consideration for transforming and decolonising the curriculum (le Grange, 2016, p. 9). The difference between her production of knowledge and her being a teacher was blurred (see Kincheloe, 2011). Engaging the IK holder as a teacher in higher education revealed the power of difference, the power of multiple ways of interpreting reality and multiple perspectives, which Kincheloe (2008) referred to as multilogicality. The transformative potential of multilogicality became evident in this study because it enabled these pre-service teachers to develop a heightened consciousness of the type of Life Sciences teachers they can become.

\section{Theme 2: The what of incorporating IKS into a module in the curriculum and} how this can create spaces for transformation

The what of creating a culturally inclusive curriculum was inextricably linked to human needs, especially in the context of the pre-service teachers' communities where health challenges are exacerbated by economic deprivation. The following excerpts from field trip questionnaires and garden portfolios provide details of what the pre-service teachers chose to plant, and how this could be used by their communities and themselves.

QP10: Indigenous knowledge makes our lives easier ... [we] do not [need to] consume [spend] a lot of money. For example, use indigenous plants to heal a flu.

QP24: Traditional knowledge helps people heal themselves without the need for money. It encourages agricultural practices and ignites business potential.

QP26: [We learned] several methods of planting and the plants are healthier since no chemicals are used.

The personal value of IK also underpinned the pre-service teachers' choice of plants to cultivate. They saw the link between IKS and their lived experiences, and the advantage of engaging with what Heleta (2016b) refers to as African-centered epistemic perspectives.

QP5: Scientific knowledge from its foundation is different from indigenous knowledge. Not all of us want medicines which are scientifically prepared, some of us prefer the old method of medication to treat diseases.

QP46: I would use these plants for my own health and suggest them to others because it is easy to grow them, they do not need much water as they are indigenous plants ... we will not get side effects.

This marked the possibility of decolonisation and transformation of the curriculum, because they refused to consume Western medicinal remedies blindly, and instead, turned their attention to the benefits of African medicinal plants. These views expressed in the questionnaires matched the work that was documented in portfolios of evidence.

Group 3 developed the garden shown in Figure 1, to manage colds and influenza. 


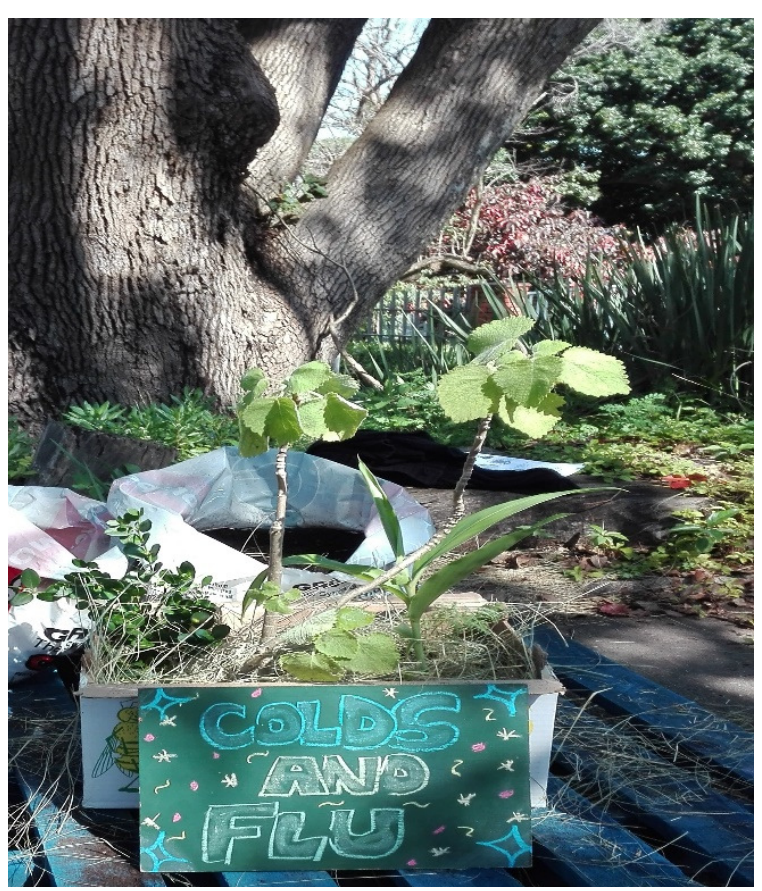

Figure 1: Medicinal garden cultivated by Group 3

Group 3 presented their choices of plants in a table.

Table 1: Uses of African Indigenous medicinal plants

\begin{tabular}{|l|l|l|}
\hline Plant & Nutrients & Usefulness \\
\hline Iboza & $\begin{array}{l}\text { Antimicrobial } \\
\text { agents }\end{array}$ & Malaria, cough, sore throat, bronchitis \\
\hline $\begin{array}{l}\text { Iziphephetho } \\
\text { (African } \\
\text { ginger) }\end{array}$ & $\begin{array}{l}\text { Vitamin B3 } \\
\text { Vitamin B5 } \\
\text { Antiseptic agents }\end{array}$ & Influenza, nausea \\
\hline
\end{tabular}

GP3: This plant in the middle is Iboza and is used to cure bronchitis. There is also African ginger which we call Iziphephetho which helps with nausea and flu. These plants are easily accessible in comparison to processed products, for example, pills. The plants are safe to use because they have no added chemicals. The traditional lady showed us how to make the medicine for Iboza. Infuse the leaves in hot water for 10 minutes and drink that water like a tea. She showed us the roots of Iziphephetho can be dried and ground and put in water to drink.

Group 2 planted, among other crops, amadumbe and imifino, shown in Figure 2. Other plants in this mixed garden were carrots, beetroot, and tomatoes. The target population of this group was people in their communities who had poor vision. 


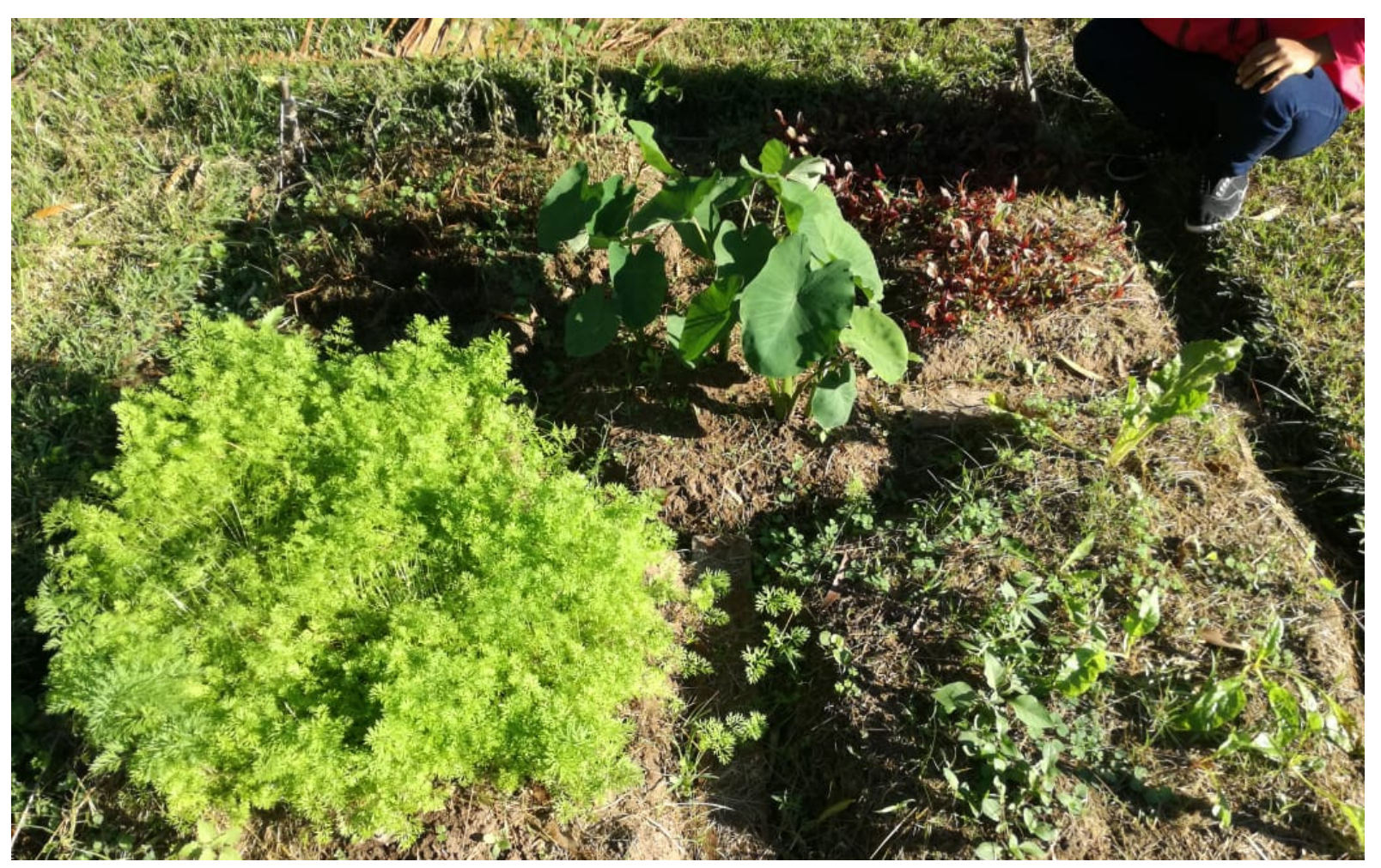

Figure 2: Food garden for health cultivated by Group 2

Group 2 presented a table to show the usefulness of each plant for eye health.

Table 2: Indigenous and non-indigenous plants for promoting eye health

\begin{tabular}{|l|l|l|}
\hline Plant & Nutrients & Usefulness \\
\hline Carrots & $\begin{array}{l}\text { Vitamin A } \\
\text { Vitamin E }\end{array}$ & $\begin{array}{l}\text { Keeps the eyes healthy. Improves vision. Reduces risk } \\
\text { of age-related macular degeneration. }\end{array}$ \\
\hline Tomatoes & Vitamin A & Promotes good functioning of retina \\
\hline Amadumbe & $\begin{array}{l}\text { Anti-oxidants } \\
\text { Beta carotene }\end{array}$ & Maintain good eye health \\
\hline Beetroot & $\begin{array}{l}\text { Lutein } \\
\text { Phytochemicals }\end{array}$ & Good eyesight \\
\hline $\begin{array}{l}\text { Imifino/ } \\
\text { Morogo }\end{array}$ & $\begin{array}{l}\text { Vitamin A } \\
\text { Vitamin E } \\
\text { Iron }\end{array}$ & Prevents free radicle damage and is good for eye health \\
\hline
\end{tabular}

This group focused on indigenous and non-indigenous crops that promote eye health. Preservice teachers indicated that these plants were particularly useful to poor communities because

the clinics and hospitals are always full [of people]. Sometimes people do not get medication or glasses because it has run out and they do not have money to see a private eye doctor. Teaching them about these plants will be highly beneficial. (GP2). 
This marked a decentring of Western knowledge and the production of that "third space" (le Grange, 2016, p. 10) in which different knowledges can function together to create an accountable curriculum.

These pre-service teachers valued indigenous plants for the addressing of health conditions, to consume as nutrient-dense food, and for coping to some extent with the poverty that makes health care inaccessible. This is significant because self-reliance through appropriating African knowledge (Kiti, 2013) was clearly articulated by participant 24 who asserted that "traditional knowledge helps people heal themselves." Onwu and Mosimege (2004) have emphasised that the benefits of IK lie in its localised, community-responsive nature, and, in this study, these advantages became evident. The pre-service teachers' explanations for selecting specific plants were embedded in a deep understanding of the contexts of people and their lived experiences, and a respect for African heritage. This marked a divergence from the parochial cause-effect explanations that characterise Western epistemology and recalled le Grange's (2014) conceptualization of currere as an active force in unleashing expressions of Africanisation, and signaled a space for curriculum transformation.

Learning about the value of these indigenous plants prompted me to search for more information. I found that research into the value of African indigenous plants is taking place internationally on a large scale. Its reach beyond the association with cultural heritage towards pharmaceutical innovations which marks the interfacing of IKS with other knowledge systems, is increasing (DST, 2004). The importance of leafy green indigenous African vegetables, such as imifino, has been underscored in several research studies (Jansen van Rensburg et al., 2007; Maseko et al., 2018; Nkobole-Mhlongo, 2016). Roots of plants such as iziphephetho (African ginger) is a prized herbal medicine used to treat a multitude of conditions given its antiseptic properties (Herbal Africa, 2016). Amadumbe, a root vegetable, is well known for its role in regulating blood glucose levels, among its other health promoting properties (Mawoyo, 2017). The antimicrobial activity of iboza (Tetradenia riparia) has also been studied extensively and its effectiveness proven through laboratory testing ( $\mathrm{Njau,}$ Alcorn, Buza, Chirino-Trejo, \& Ndakidemi, 2014).

Having been taught the IK-infused module by an IK holder who used different pedagogical approaches, what they learned about what they could choose to plant along with the contexts in which these plants could be used, created a change in these pre-service teachers at a deeper level. Through decolonising the curriculum by repositioning the pedagogy and the pedagogue in higher education, these pre-service teachers were galvanised into "rediscovering and recovering" (Chilisa, cited in le Grange, 2016, p. 3) their culture. The importance they attached to reclaiming indigenous knowledge was evident.

QP18: As teachers we should fight for traditional knowledge to be taught at schools. Traditional knowledge plays a significant role in the lives of many.

QP22: Having a traditional knowledge holder in education is highly beneficial and ... provides us with a wide range of knowledge that cannot be found in books. 
QP24: Traditional knowledge helps Africans and other people to heal themselves ... seeing people further their studies in traditional medicine is really wonderful. It shows that not all of us are lost and that not all things that help heal us when we are sick is Western.

QP45: The traditional knowledge holder allows you to learn and grasp hidden knowledge.

A few pre-service teachers adopted an almost activist role in reclaiming IK into the main system of knowledge production. They called for this hidden knowledge that, according to Heleta (2016b) and Kruger and Fataar (2017) has been excluded from the curriculum and denigrated during centuries of exploitation and subjugation, to be reappropriated, and taught formally in the school curriculum. The role of indigenous knowledge in enabling "Africans and other people to heal themselves" as articulated by QP24, echoes Hountonji's (2009) advocacy for a focus on knowledge that addresses problems of Africans and develops selfreliance. The assertion that "it shows that not all of us are lost and that not all things that help heal us when we are sick is Western" is powerful. It reveals an unveiling by this pre-service teacher of what Kincheloe (2008) thinks of as ideological and epistemological inscriptions of mainstream knowledge frameworks, and the epistemic violence that occurs when people become lost, as it were, because their knowledge systems are subjugated (Heleta, 2016b).

Several possibilities for the transformation and decolonisation of the module in the teacher education curriculum that was infused with IK, became visible. First, there should be deep reflection and analysis of what constitutes the professional identity of an authentic teacher in

higher education (HE). A teacher whose knowledge is embedded in lived experience could be better suited to become an HE pedagogue, but then so could those of us who are taking this lesson to heart. Second, using instructional strategies that favour an inquiry approach and concrete materials, with which students can interact using their senses, is recommended. Third, selecting settings and curriculum content, using pedagogical strategies that point to teachers' and students' lived experiences, is valuable. Finally developing curriculum activities that depart from the goal of mastering sterile facts, and favouring knowledge that is responsive to social needs, is vital.

\section{Concluding remarks}

I have argued for the recentering of African voices and philosophies in the remaking of an intellectual culture, but I do not favour the reproduction of the notion of a single hegemonic episteme to be mastered. Therefore, following Kruger and Fataar (2017) I have drawn on a plurality of voices in order to re-imagine how the university curriculum can be democratised. Using insights from le Grange's concept of Ubuntu-currere and an emergent Indigenous paradigm (2016), Kincheloe's transformative multilogicality (2008), and Hountonji's (2009) call for an "African-based tradition of knowledge" (p. 9), I found an IK holder and positioned her as a legitimate teacher in a, HE education course.

In keeping with Hountonji's (2009) reminder of knowledge production that enables us to meet the natural needs of African societies, and Kruger and Fataar's (2017) advocacy for a 
human-centric orientation to knowledge, these pre-service teachers selected plants that helped to alleviate specific health conditions among people in their communities. By tapping into locally based and locally produced indigenous knowledge that, as mentioned above, several pre-service teachers described as hidden knowledge and by interweaving this with other forms of knowledge, they blurred the lines between indigenous and colonial, and between non-western and Western knowledge. This interweaving of knowledge in its use of the power of diverse perspectives created a platform for the university curriculum as a "trading zone for intercultural exchange" (Kincheloe, 2008, p. 7).

Kincheloe (2008) described the digression from the monocultural perspectives of who is the legitimate knower, what is legitimate knowledge, and how it is produced in higher education, as "crawling through a new curriculum wormhole" (p. 8). In this study, I created a new curriculum wormhole by drawing on previously marginalised IK and on an IK holder's expertise and ability to re-imagine who can teach, how they can teach, and what they can teach. The status quo was disrupted by my finding and using a teacher who incorporated unconventional pedagogical strategies that did not mirror the so-called normal learning spaces in HE. In addition, this led to the pre-service teachers' understanding of how this can alleviate the suffering of people in their communities. The pre-service teachers identified "what knowledge is [of] most worth" (le Grange, 2014, p. 1285) in their local contexts. This disruption of the epistemological status quo has the potential to shape their teacher identity in ways that enable them to develop their curricula and pedagogy by drawing from and contributing to a home-grown African epistemology.

With reference to Chilisa's (2012) five phases of decolonisation (cited in le Grange, 2016), I mourned the insidious ways in which the original module, as part of the university curriculum, had perpetuated epistemic violence by silencing alternative knowledge systems. The pre-service teachers, the IK holder, and I entered the dreaming, commitment, and action phases by using activities based on the voice and methods of an IK holder in the curriculum. This allowed for transformation and cognitive justice in its encouraging of pre-service teachers to engage in the first of these phases-rediscovering and recovering the IK that is so much a part of their culture.

\section{References}

Bentz, V. M., \& Shapiro, J. J. (1998). Mindful enquiry in social research. Thousand Oaks, CA: Sage.

Bertram, C., \& Christiansen, I. (2014). Understanding Research. An introduction to reading research. Pretoria, RSA: van Schaik.

Ciaffa, J. A. (2008). Tradition and modernity in postcolonial African philosophy. Humanitas, XXI (1), 121-145.

Connell, R. (2016). Decolonising knowledge, democratising curriculum. Retrieved from https://www.uj.ac.za/faculties/humanities/sociology/PublishingImages/Pages/Seminar 
s/Raewyn\%20Connell's\%20Paper\%20on\%20Decolonisation\%20of\%20Knowledge.p df

de Beer, J., \& Petersen, N. (2016). Decolonisation of the Science curriculum: A different perspective (\#Cookbook-Labs-Must-Fall). Proceedings from ISTE International Conference on Mathematics, Science and Technology Education: Towards Effective Teaching and Meaningful Learning in Mathematics, Science and Technology. Retrieved from http://hdl.handle.net/10500/22869

Department of Basic Education (DBE). (2011). National Curriculum Statement (NCS): Curriculum and Assessment Policy Statement (CAPS). Further Education and Training Phase: Grades 10-12. Pretoria, RSA: Government Printer.

Department of Science and Technology. (2004). Indigenous Knowledge Systems. Republic of South Africa: Department of Science and Technology.

Gray, D. E. (2013). Doing research in the real world (3rd ed.). Thousand Oaks, CA: Sage.

Groenewald, T. (2004). A phenomenological research design illustrated. International Journal of Qualitative Methods, 3(1). Article 4. Retrieved from http://www.ualberta.ca/ iiqm/backissues/3_1/pdf/groenewald.pdf

Heleta, S. (2016a). Decolonization of higher education: Dismantling epistemic violence and Eurocentrism in South Africa. Transformation in Higher Education, 1(1), 1-8.

Heleta, S. (2016b). Decolonisation: Academics must change what they teach, and how. Retrieved from https://theconversation.com/decolonisation-academics-must-changewhat-they-teach-and-how-68080

Herbal Africa. (2016). Retrieved from http://www.herbalafrica.co.za/africanginger.html

Hountonji, P. J. (1983). African philosophy: Myth and reality. Bloomington, IN: Indiana University Press.

Hountonji, P. J. (2009). Knowledge of Africa, Knowledge by Africans: Two perspectives on African studies. RCCS Annual Review, 1. Retrieved from http://www.ces.uc.pt/publicacoes/annualreview/media/2009\%20issue\%20n.\%201/AR 1_6.PHountondji_RCCS80.pdf

Jansen, J. (2017). Introduction-Part II. Decolonising the university curriculum given a dysfunctional school system? Journal of Education, 68, 3-13.

Jansen van Rensburg, W. S., van Averbeke, W., Slabbert, R., Faber, M., van Jaarsveld, P., Wenhold, F., \& Oelofse, A. (2007). African leafy vegetables in South Africa. Water SA, 33(3), 310-326. 
Jautse, P. vP., Thambe, N., \& de Beer, J. (2016). A day at the museum: A case study of how museums could partner with universities in teacher education. Proceedings from ISTE International Conference on Mathematics, Science and Technology Education: Towards Effective Teaching and Meaningful Learning in Mathematics, Science and Technology. Retrieved from http://uir.unisa.ac.za/bitstream/handle/10500/22895/Phemelo\%20Paige\%20Jautse\%2 C\%20Nicholas\%20Thambe\%2C\%20Josef\%20de\%20Beer.pdf?sequence=1\&isAllow $\mathrm{ed}=\mathrm{y}$

Kincheloe, J. L. (2008). Critical pedagogy and the knowledge wars of the twentieth century. Retrieved from http://freire.education.mcgill.ca/ojs/public/journals/Galleys/IJCP011.pdf.

Kincheloe, J. L. (2011). Critical ontology and indigenous ways of being: Forging a postcolonial curriculum. In J. L. Kincheloe, K. Hayes, S. R. Steinberg, \& K. Tobin (Eds.). Key works in critical pedagogy (pp. 333-348). Rotterdam, NL: Sense.

Kiti, P. C. (2013, October). Recentring Africa: From Paulin Hountonji to Meinrad Herbga. Paper presented at the meeting of the International Conference of Science and Indigenous Knowledge Project at University of Western Cape, Cape Town, RSA.

Kruger, E., \& Fataar, A. (2017). Decolonising education in South Africa: An interview with Aslam Fataar. University Seminar, 23 January. Retrieved from https://www.litnet.co.za/decolonising-education-south-africa-interview-aslam-fataar/

le Grange, L. (2014). Currere's active force and the Africanisation of the university curriculum. South African Journal of Higher Education, 28(2), 1283-1294.

le Grange, L. (2016). Decolonising the university curriculum. South African Journal of Higher Education, 30(2), 1-12.

Letsekha, T. (2013). Revisiting the debate on the Africanisation of higher education: An appeal for a conceptual shift. The Independent Journal of Teaching and Learning, $8(1), 5-18$.

Maree, K. (2016). First Steps in Research (2nd ed.). Pretoria, RSA: van Schaik.

Maseko, I., Mabhaudhi, T., Tesfay, S., Araya, H. T., Fezzehazion, M., \& du Plooy, C. P. (2018). Sustainability, 10, 1-16. doi:10.3390/su10010016.

Mawoyo, B. (2017). Influence of growth locations on physicochemical properties of starch and flour from amadumbe (Colocasia esculenta) genotypes (Unpublished master's thesis). Durban University of Technology, Durban, RSA. 
Millar, R. (2004, October). The role of practical work in the teaching and learning of science. Paper presented at the meeting of High School Laboratories Role and Vision, Washington, DC.

Molefe, T. O. (2016). Oppression must fall: South Africa's revolution in theory. World Policy Journal, 33(1), 30-37.

Motta, S. C. (2013). Teaching global and social justice as transgressive spaces of possibility. Antipode, 45(1), 80-100. Retrieved from https://onlinelibrary.wiley.com/doi/pdf/10.1111/j.1467-8330.2012.00995.x

Njau, E. A., Alcorn, J., Buza, J., Chirino-Trejo, M., \& Ndakidemi, P. (2014). Antimicrobial activity of Tetradenia riparia (Hochst.) Lamiaceae, a medicinal plant from Tanzania. European Journal of Medicinal Plants, 4(12), 1462-1478.

Nkobole-Mhlongo, N. (2016). Local leafy greens to the rescue. NRF/SAASTA. Retrieved from https://sciencetoday.co.za/2016/11/14/local-leafy-greens-to-the-rescue/

Onwu, G., \& Mosimege, M. (2004). Indigenous Knowledge Systems and science and technology education: A dialogue. African Journal of Research in SMT Education, $8(1), 1-12$.

Ruddock, P. (2018, March 9). Decolonising education in South Africa. OPINION. Retrieved from https://www.iol.co.za/news/opinion/decolonising-education-in-south-africa13679313

Sayed, Y., Motala, S., \& Hoffman, N. (2017). Decolonising initial teacher education in South African universities: More than an event. Journal of Education, 68, 59-91.

Schiro, M. S. (2008). Curriculum theory: Conflicting visions and enduring concerns. Los Angeles, CA: Sage.

Shay, S. (2016). Decolonising the curriculum: It is time for a strategy. Retrieved from https://theconversation.com/decolonising-the-curriculum-its-time-for-a-strategy60598

Singh, C. K. S., Samad, A. A., Hussin, H., \& Sulaiman, T. (2015). Developing a portfolio assessment model for the teaching and learning of English in Malaysian L2 classroom. English Language Teaching, 8(7), 164-173.

Strange, V., Forest, S., Oakley, A., \& The Ripple Team. (2003). Using research questionnaires with young people in schools: The influence of the social context. International Journal of Social Research Methodology, 4, 337-346. 
Zinyeka, G. (2013). Onwu and Mosimege on "Indigenous Knowledge Systems and Science and Technology Education: A Dialogue” Some remaining issues. Greener Journal of Educational Research, 3(9), 432-437. 